\title{
Arthrinium phaeospermum
}

National Cancer Institute

\section{Source}

National Cancer Institute. Arthrinium phaeospermum. NCI Thesaurus. Code C127682.

A species of dematiaceous anamorphic fungi in the phylum Ascomycota with smooth, hyaline, branched, septate hyphae. 